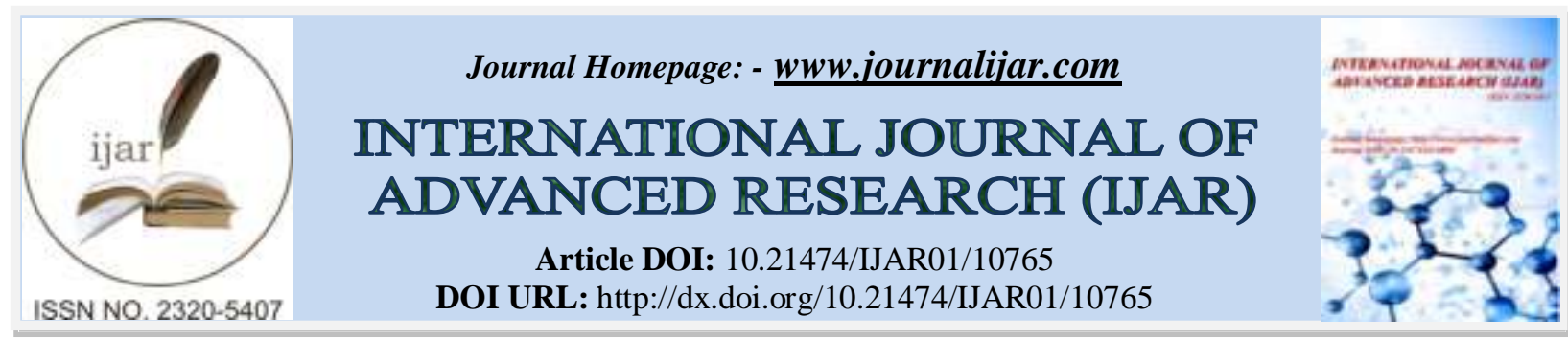

\title{
RESEARCH ARTICLE \\ DISCOURSE UNITS THAT SIGNAL CONVERSATION BREAKDOWN DURING GROUP GUIDANCE AND COUNSELLING SESSIONS
}

\author{
Teresa Siro \\ Department of Linguistics, School of Arts and Social Sciences, Maseno University P.O Box Private Bag, Maseno- \\ Kenya.
}

\section{Manuscript Info}

………...............

Manuscript History

Received: 07 February 2020

Final Accepted: 10 March 2020

Published: April 2020

\begin{abstract}
Counselling programmes in high schools in Kenya are communicative events organised in group or individual sessions to remedy social or academic issues affecting students. Particular breakdowns often arise in such conversation settings due to their informal nature and turn control necessitating conversation repair among the participants. It is therefore imperative to study the conversational nature of guidance and counseling so as to identify inconsistencies that may lead to breakdown and misunderstanding and also the effects of the repair strategies used to address them. With regard to conversation repair, the existing literature has mainly focused on a one on one conversation and classroom setting and not on a highly interactive group counseling sessions. This study, therefore, sought to examine effects of conversation repair strategies employed by teacher-counselors and student-counselees during counseling sessions in selected secondary schools in Kenya
\end{abstract}

Copy Right, IJAR, 2020,. All rights reserved.

\section{Introduction:-}

In order to achieve any meaningful results in student counseling in secondary schools, the counselor, who designs the counseling environment, must view the counseling sessions as conversational and communicative processes. The school counseling session is a process of communication that addresses problems and challenges of the student client that the teacher counselor receives for counseling (Journal of Genetic Counseling, 2001). The communication that arises from the dialogue between counselor and client in whatever setting the interlocution takes place, constitutes a discourse that is specific to this counseling encounter in the school. Pare (2001) indicates that counseling models or theories are constructed as discourses, suggesting that the school realization of a school counseling session is in its manifestation as a discourse that is socially constructed within the institutional limits of a school. Miller and Silverman (1995) argue that counseling talk can range from the portrayal of an individual's life experiences to portrayals of undesired outcomes. They further argue that the description of troubles will only be achieved when a counselor and a client monitor and respond to each other's talk.

Counseling discourses must possess certain characteristics that distinguish it from other discourses. Andera (2003) asserts that school counseling discourse has a distinct structure that comprises communicative units of Acts, which combine to form Moves, these combine to form Exchanges and exchanges form Transactions. The largest unit is identified as the Session. According to Stenstrom (1994; 38,) an act is signaling "what the speaker wishes to communicate" or "signaling the speaker's intention" (p221) An act is the smallest element in spoken discourse. One 
or more acts combine to form a move. A move is "the verbal action which carries the conversation forward" Stenstrom, (1994; 36). A move consists of one or more acts. In effect, the move is a unit which has a function relating to the progression of the conversation. Stenstrom defines an exchange as the basic unit of conversation. An exchange is composed of more than two moves (initiation and response). Stenstrom (1994) further, defines a transaction as a sequence of exchanges to perform some task in conversation. Most typically there is a boundary marker to indicate that a new transaction is beginning for example, 'okay', 'now'. The unit of Move is identified as the minimal communicative unit in terms of illocutionary acts following Austin (1962) Speech Act Theory.

\section{Statement of the Problem:}

Like any other discourse, issues of context of situation and other related extra-linguistic aspects of the discourse are important in enhancing communication. These sessions are best constructed as conversational discourse if they are to achieve maximum effects. Hence, it has become increasingly imperative to study the conversational nature of such discourses in their elements in an attempt to identify inconsistencies that may lead to breakdowns and misunderstandings.

In student group counselling conversation, the possibility of conversation repairs occurring is normal. As the counsellor and client converse, each adopts a variety of repair strategies for resolving issues and minimizing misunderstanding that may arise during conversation. However, particular breakdowns often arise in conversation due to its informal nature that would render its contents and objectives difficult to interpret thus necessitating conversation repair among the participants. The effects of these repair strategies vary and may considerably determine the outcome of the conversation discourses. This study, therefore, sought to examine the effects of these conversation repair strategies employed by teacher counsellors and clients during student group counselling sessions.

\section{Theoretical Framework: \\ The Conversation Analysis Theory:}

The study was premised on the Conversation Analysis (CA) Theory. The central purpose of Conversation Analysis as used here in the present study is to investigate the norms and conventions that speakers use in interactions to establish communicative understanding. Traditional CA was concerned only with the speech of the interlocutors as the observable external event. Normal conversation is often characterized by frequent interruptions to maintain relevance, deviate from the topic or draw attention to other issues either temporarily or completely. The principle of turn-taking has been established as one of the central interests of $\mathrm{CA}$, as it is the basic component of all conversation. The turn form, the turn content and the turn length are all of interest when examining turn-taking in conversation. These are in turn affected by the formality or informality of a situation. Turns between teachers and students, clients and lawyers, have more boundaries defined by the formal context, whereas telephone conversations among friends are freely variable and determined by elements within the interaction such as power relations (Schegloff, 1992).

Turn constructions have turn construction units that often correspond to linguistic elements such as sentences, phrases, or single words, for example, "Eh!" or "What?" The turn construction units have two prominent properties; the first one is called projectability. It is possible for a speaker to project, as the turn construction proceeds, what kind of a unit it is and when it is likely to end. This leads to the second property, transition-relevant places. These occur at the boundaries of the turn construction unit and make it possible for transition between speakers. Schegloff (1992) notes that speakers project to ideal not actual transition points because in natural spoken conversation the optimum condition is for as little time as possible to occur between turns. This is practical, since waiting for any speaker to finish completely would result in gaps that would erode the natural flow and meaning as well as the opportunity for any speaker to enter the conversation because either other speakers simultaneously interrupt or the current speaker continues.

The point of these detailed descriptions of conversational practice or use is to provide empirically grounded descriptions of how speakers interactively manage and organize communication in a myriad of social contexts and for an array of everyday social actions. Turns occur one after the other, in a serial order, however, the relationship between turns is not serial but sequential. In this study, the use of Conversation Analysis theory is informed by its specific attribute of being able to avail sequential and interpretive information as used during conversation. This concept is known as the adjacency pair sequence. The insight here is not just that answers follow questions but that responses are conditionally relevant to utterances in prior turns. The second pair part is conditional on the first, it is 
normative. The normative constraints on adjacency pairs are important to CA because the researcher can draw inferences in the cases where typical responses do not occur. For example, a lack of an answer to a question may imply evasion. Moreover, the resolution of the meaning of the break in normative constraint is confirmed in subsequent turns through the next-turn proof procedure (Sacks, Schegloff \& Jefferson, 1974).

One key element of CA, and which the current study referred to, is that concerned with the occurrence of 'trouble', such as mishearing, misunderstanding, the speaker being unable to find a word, or the statement of incorrect information. Such difficulties are resolved through a 'repair', which may be of self- or other-initiated, and self- or other- repaired. The preference is always for self-initiation and self-repairs. Moreover, one further body of theory which has immediate relevance to Conversation Analysis is that relating to the construction of meaning in a conversation. Such theory includes aspects of pragmatics theory, combined with aspects of speech act theory (Searle, 1979).

Conversational repair devices were initially developed by Kenworthy $(1984 ; 1986)$ to study the conversation interactions of children with hearing impairment and their caregivers. The strategies have been successfully applied to adult-adult interactions, although, not necessarily to address hearing impairment, but rather to facilitate the flow of conversation without unwanted deviations. Subsequently, Kenworthy developed a typology of conversational repair strategies indicated in Figure 1:

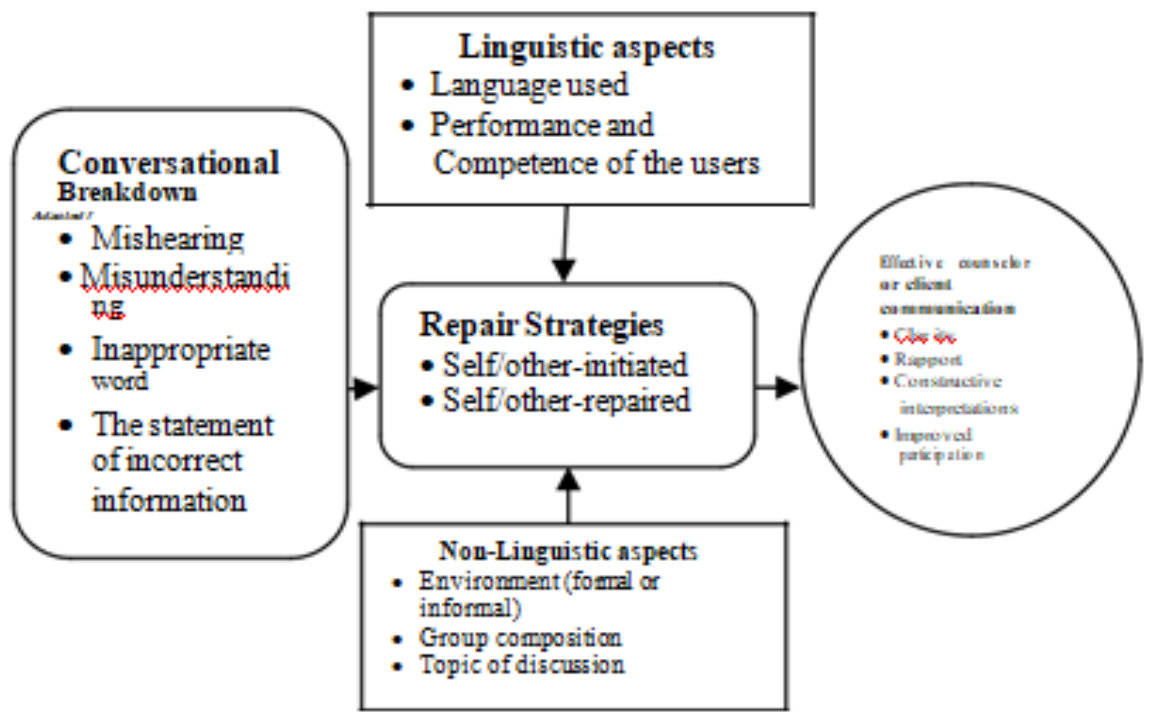

Figure 1:- Theoretical Framework.

\section{Adapted from Schegloff et al 1977:}

The theoretical framework in Figure 1 is a graphical representation of the relationship between the features of conversational breakdown which include mishearing, misunderstanding, inappropriate word, and the statement of incorrect information and the effect they are expected to have on counselling discourse during students' group counselling sessions. These are the input and output respectively and are moderated by the processes which were essentially the linguistic and non-linguistic and conversational repairs observed during conversation. These are observed as they act through the processes governed by linguistic aspects like language used, performance and competence of the users and non-linguistic aspects like the environment, the group composition and the topic of discussion as well as the conversational repairs employed by interlocutors. The effectiveness of the counsellor and client communication is predicated on improved clarity, rapport, constructive interpretations and participation.

\section{Reviewed Literature:-}

Discourse units as signals of repair strategies are a vital component for analysing spoken discourse as well as written discourse. However, in spite of its crucial role in discourse segmentation, there is no consensus in the literature on what a minimal discourse unit (MDU) is and how it should be identified. According to Degand and Simon (2007), the minimal discourse unit should be defined in terms of two linguistic criteria: syntax and prosody. They develop a 
heuristics for identifying minimal discourse units in (spoken) discourse and illustrate this with a piece of spontaneous conversation.

In discourse analysis it is commonly acknowledged that discourse is (hierarchically) structured (Mann \& Thompson, 1987; Roulet et al., 2001). The assumption is that a piece of discourse is built up from smaller "building blocks" related to one another in a coherent way. What these building blocks actually look like differs according to the discourse model at stake. Mann and Thompson (1988) content themselves with stating that the minimal units are "typically clauses". According to Degand and Simon (2007), most of the authors tackling explicitly the theoretical issue of defining MDUs acknowledge their bi-dimensional status with a linguistic face (in the form of syntactic clauses) and a textual face (in the form of contextualised information units).

On the basis of Selting's (2000) work on Turn-Constructional Units ( TCU) in the framework of Conversation Analysis, this study shares the multi-dimensional view of Minimal Discourse Units (MDU) and considered them as being the smallest interactionally relevant complete linguistic unit(s), in a given context, that is constructed with syntactic and prosodic resources within their semantic, pragmatic, and sequential context.

Understanding a piece of discourse is an incremental process in which new segments are integrated with the preceding ones to construct a coherent mental representation of the discourse content. Consequently, MDUs can be defined as devices for updating this representation (Van Dijk, 1999). However, the general problem of this assertion is that they do not make explicit the link between the textual segments and the conceptual ideas they vehicle, since the mental representations are composed of concepts (ideas), not of linguistic sentences.

Hannay and Kroon (2005) propose a link between strategic units (acts) and conceptual units (ideas). The conceptual units correspond to the conceptual content of the discourse, individualized in the form of ideas thus, they are abstract entities involved in text processing (production and comprehension), but not as such materialised within the discourse. Following Chafe (1992), discourse units come in three types: (i) fragmentary units are truncated, and will at this stage be disregarded from the analysis; (ii) substantive units convey ideas of events, states or referents; (iii) regulatory units, regulate the interaction of information flow; that is, the development of discourse, the interaction between participants, the expression of the speaker's mental process, and/or the judgment of the validity of the information. According to this study, substantive and regulatory units were used to contribute to the mental representation of the ongoing discourse.

According to Degand and Simon (2007), a workable set of segmentation principles implies the use of explicit criteria, that is, criteria based on observable, linguistic features. They provide the discourse analyst with a two-steps procedure: (i) segmenting the flow of speech into MDUs, and (ii) distinguishing between the three types of units: fragmentary, substantive and regulatory. Though this study did not use these distinguishing features as suggested, it however focused on spoken discourse and identified syntactic units as MDUs to be used for analysis of conversational repair signals in discourse.

Syntactic units comprise a nucleus (mostly verbs, but also nouns or adjectives) accompanied with all its dependants. Each nucleus may govern various kinds of dependants. The major distinction is that between elements governed by the verb (actants and circumstants) and those that are not (adjuncts or associated elements), a difference that can be described in syntactic terms. Governed elements, have an interrogative pronominal counterpart, while associated elements have not. Intonation units are identified in terms of major intonation boundaries described by Mertens (1993) as a sequence of syllables grouped by a final accent carrying a high tone projecting more to come or a low tone signaling finality, which are usually signaled by the presence of silent pause. In the current study, these syntactic and intonation units formed the basis for the analysis of discourse units signaling conversational repair in school group counselling discourse.

\section{Methodology:- \\ Research design:}

This was a qualitative research that set out to examine discourse units that signal conversation breakdown. The study adopted analytical research design which is suitable for qualitative research. Analytical research design involves knowledge of the target language by the researcher, but rather than accessing intuitions directly, the researcher bases generalizations upon an independently collected data (Milroy, 1987). The researcher applied analytical design in 
identifying the underlying themes in the construction of the meaning of and in texts that were observed and recorded during teacher-counsellor and students' conversations as well as recordings of face to face interview with teachercounsellors.

\section{Area of study:}

The study was confined to effects of repair strategies used to resolve conversation breakdowns which forms part of the wider conversational analysis theoretical study area. The study chose an institutional setting where talk is structured along topics and the features of conversation being investigated were observed. Students' group counselling sessions were chosen because they were more interactive, well timed and semi-formal conversations on particular topics. These topics were those affecting adolescents who are confronted with issues that they are not so conversant with or do not understand. In this study, Kakamega Central Sub-county was chosen among other areas by the researcher due to availability of Secondary schools that practice students group counselling as a means of addressing the students' academic and social concerns. The area was also accessible to the researcher and this made the research manageable.

\section{Study population:}

The study targeted group counselling sessions conducted in the schools by teacher counsellors and studentcounselees in secondary schools in Kakamega Central Sub- county. The eight schools that were available for the study, each conducted at least one group counselling session per month, however, three schools conducted six sessions during the five months of the study. Therefore the total number of sessions available for the researcher was 43. The unity of analysis was the utterances within the discourse during the group guidance and counselling sessions.

\section{Sample size:}

Purposive sampling was used in this research to obtain the required sample size. Purposive sampling is useful in qualitative research especially in cases where the data illustrates characteristics of particular subgroups of interest and also comparison and the investigator relies on his or her expert judgment to select units that are representative or typical of the population (Patton, 1999). The study purposively sampled thirteen counselling sessions in eight secondary schools both private and public within the study area. The thirteen sessions constituted thirty percent of the forty-three sessions that were conducted during the study period. According to Mugenda and Mugenda (2003), the minimum size of sample should be thirty percent of the population when using small populations. The sessions used in the study were those that had been programmed to take place in the identified schools in the study area. The sessions lasted between forty-five minutes to one hour each and were all conducted in the afternoon. Afternoon was appropriate since there was adequate time for counselling sessions particularly during lunch break and after classes. Students in the session were those who had been identified by the teacher- counsellor and attended the group guidance and counselling sessions in the target schools. Teachers used in the study were the eight teachercounsellors from the eight selected secondary schools in the sample. The sessions used in the sample were those that the counsellor and the clients allowed the researcher to observe. These were small group guidance and counselling sessions comprising between four to nine students and one teacher-counselor. The group guidance and counselling sessions were suitable for the study because of their interactive nature which involved responses from the studentcounsellees and teacher-counsellors in order to arrive at solutions on important questions and problems. This enabled the researcher to observe the repair strategies.

\section{Analysis and Discussion:-}

Data collected was analysed using mixed method along thematic lines. However the analysis was skewed towards qualitative method. Through this form of analysis, major topics were identified and categorised. Data collected was organised and categorised following qualitative content analysis. This was done by first extracting the utterances that constituted breakdowns and repairs within the transcribed conversations and analysed within the context. Titscher, Meyer, Wodak and Vetter (2000), observe that the core and central tool of any content analysis is its system of categories; every unit of analysis must be coded that is allocated to one or more categories. Bryman (2004), posits that qualitative content analysis is probably the most prevalent approach to qualitative analysis, it comprises a searching- out of underlying themes in the material being analysed. He specifically defines qualitative content analysis as an approach to documents that emphasise the role of the investigator in the construction of meaning of and in texts. There is an emphasis on allowing categories to emerge out of the data and on recognising the significance for understanding the meaning of the context in which an item being analysed appeared. In addition, conversation analysis procedure was used during data analysis. Conversation analysis may be conceived as a 
specific analytic course which may yield insight in the ways in which members of society interact during conversation (Atkinson and Heritage, 1984). Data for study in conversation analysis must be actual talk occurring in natural contexts (Heritage, 1995). Conversation analysis is analysis of a real-world, situated, contextualized talk. Since the system used in CA is specifically designed to reveal the sequential features of talk, the researcher examined the adjacency pairs as they occurred in the discourse. The process entailed the identification of the repair strategies following the typology set out by Kenworthy (1984) as well as additional patterns emerging from observations during the counselling discourse. The first level of analysis involved transcription of the verbal content from the audio tape and subsequent selection of relevant pieces of corpus for investigation. This was done immediately after each counselling session to avoid the volume of work resulting from them. The second level involved identification of conversation repair strategies from selected excerpts. These were then grouped according to the conversation breakdown and repair categories identified in the study. The researcher was able to identify the conversation breakdowns, conversation repair strategies and repair categories through multiple reading of the transcripts. The researcher also used the notes taken from observations of non-verbal features to supplement analysis of the data. Transcripts of the face-to -face interview with teacher-counsellors were also used to compare responses by the participants of the group counselling sessions and provide additional narratives for explaining some of the occurrences in the sessions. Theses enabled the investigator to get a general sense of the information and began to capture important aspects of the data. The categories identified the occurrence of the breakdowns, the type of requests for clarification used by the subjects to resolve the breakdowns as well as the types of repair strategies provided by the interactants. Communication breakdowns were defined as interruptions in the flow of conversation resulting from the counsellor's or client's misperceptions of the partner's message. This included speaking turns where the subjects' misperception was evidenced by either their use of requests for clarification, inappropriate responses to the partner's turn, abrupt topic shifts or inappropriate word.

Further a distinction was made between those communication breakdowns that were followed by requests for clarification repair. The type of requests for clarification initiated by the subjects to resolve communication breakdowns was identified as either nonspecific requests for clarification or specific requests for clarification. Specific requests for clarification were further divided to include requests for repetition of a specific constituent and request for a change in manner of presentation of the message. The interlocutor responses elicited by the requests for clarification were classified as exact or partial repetition, repetition of specific constituent, confirmation, elaboration and paraphrase. Data was analysed according to patterns of repair trajectory and specific repair types and whether or not the repair was successful. Finally data was presented in prose.

\section{Recommendations:-}

It emerged that conversation repair strategies in school group guidance and counselling sessions are signaled by syntactic and prosodic units in the discourse. However, these discourse units are limited since in the group guidance and counselling sessions, the participants had varying levels of linguistic performance and what might not have constituted a breakdown in one setting ended up occasioning a breakdown in another. The study recommends that counsellors involved in group guidance and counselling need to monitor the flow of conversations during the sessions to keep them within context. There is also need to choose or allow the use of language that majority of the group members understand and can easily communicate in. This will minimize instances of trouble sources that necessitate need for repairs. Since most of the teacher-counsellors are responsible for moderating the discourse, they should learn to use appropriate words at turns in order to clearly articulate what they have in mind. This is because in most cases, students might not ask the teacher-counsellors to repair defective segments of their talk.

\section{References:-}

1. Andera, A. (2003). Structure and Pragmatic Features in School Counselling Discourse: A Case Study of Secondary Schools in Nairobi. Unpublished MA Thesis. Kenyatta University. Kenya.

2. Austin, J. L. (1962). How to do things with words. Oxford: Clarendon Press.

3. Bryman, A. (2004). Social Research Methods (2rd ed) New York: Oxford University Press.

4. Chafe, W. (1994). Discourse, consciousness and time. Chicago: The University of Chicago Press.

5. Schiffrin, D. (1994). Approaches to discourse. Cambridge: Blackwell Publishers Ltd.

6. Degand L. \& Simon A. C. (2007). Minimal Discourse Units: Can we define them, and why should we? Centre for Text and Discourse Studies. FNRS/Université catholique de Louvain

7. Hannay, M. \& Kroon, C. (2005). Acts and relationship between discourse and grammar. Functions of Language, 12: $87-124$ 
8. Heritage, G. (1995). Conversation analysis: Methodological aspects. In Quasthof, U. (ed.) Aspects of oral communication. Berlin/ New York: Walter de Gruyter 391-418.

9. Kenworthy, O.T. (1984). The influence of selected discourse and auditory factors upon language acquisition of hearing-impaired children. Unpublished Doctoral Dissertation, University of Wisconsin- Madison.

10. Journal of Genetic Counselling (2001). Volume 10, Issue 2, pp 133-150

11. McRoy, S \& Hirst, G. (1995). The repair of speech act misunderstanding by abductive inference. Computational Linguistics, 21 (4): 435-478.

12. Mann, C. W. \& Thompson, S. A. (1987). Rhetorical structure theory: A framework for the analysis of texts. International Pragmatics Association Papers in Pragmatics, 1, 79-105.

13. Mertens, P. (1993). Intonational groupings, boundaries and syntax structure in French. In House, D. \& Touati, P. (Eds.). Proceedings of ESCA workshop on Prosody, Lund (s) Working Papers 41,156-159.

14. Miller, G. \& Silverman, D. (1995). Troubles talk and counselling discourse: A Comparative study. Sociological Quarterly, 36, (4). 725-747.

15. Milroy, L. (1987). Observing and analysing natural Language. New York: Blackwell Publishers

16. Mugenda, M. O. \& Mugenda, G. A. (2003). Research methods: Quantitative and qualitative approaches. Nairobi: Laba Graphics Services.

17. Patton, M. Q. (1999). Qualitative evaluation and research methods ( $2^{\text {nd }}$ ed.). Newbury Park, CA: Sage.

18. Roulet, E. (2000). The analysis of dialogue in one modular structures of discourse approach: The example of novelistic dialogue. In F. Hundenurscher \& E. Weigand (eds), Future Perspectives of Dialogue Analysis. Tubingen: Niemeyer, pp. 1-34.

19. Sacks, H., Schegloff, E. A. \& Jefferson, G. (1974). A simplest systematic for the organization of turn-taking for conversation. Language, 50, 696-735.

20. Schegloff, E., Jefferson, G. \& Sacks, H. (1977). The preference for self-correction in the organization of repair in conversation. Language, 53, 361-382.

21. Schegloff, E. A. (1992). Repair after next turn. The last structurally provided defense of intersubjectivity in conversation: American Journal of Society, 98, 1295-1345

22. Searle, J.R. (1979). Taxonomy of illocutionary acts. Cambridge: Cambridge University Press

23. Selting, M. (2000). The Construction of units in conversational talk. Language in Society. 29 (4) 477-517.

24. Stenstrom, A. B. (1994). An introduction to spoken interaction. London: Longman.

25. Titscher, S., Meyer, M., Wodak, R. \& Vetter, E. (2000). Methods of text and discourse analysis. London: Sage.

26. Van Dijk, T. (1999). Context model in discourse processing. In Van Oostendorp, H., \& Goldman, S. R. (Eds). The construction of mental representations during reading. Mahwah, NJ. USA. Lawrence Erlbaum Associates. pp 123-148. 